\title{
A Method for Debris Flow Management Based on Numerical Simulation
}

\author{
Jun Wang ${ }^{1,2}$, Qinghua Gong ${ }^{1,2}$, Haixian Xiong ${ }^{1,2}$, Xiaoling Yin ${ }^{1,2}$, Shun Yang ${ }^{3}$ \\ ${ }^{1}$ Guangdong Open Laboratory Of Geospatial Information Technology and Application, Guangzhou \\ 510070, China \\ ${ }^{2}$ Guangzhou Institute of Geography, Guangzhou 510070, China \\ ${ }^{3}$ Technical Centre for Geological Hazard Prevention and Control, CGS, Institute of Exploration \\ Technology, CAGS, Chengdu 611734, China
}

\section{基于数值模拟的泥石流风险管理途径及方法探索

\author{
王钧 ${ }^{1,2}$, 宫清华 ${ }^{1,2}$, 熊海仙 ${ }^{1,2}$, 尹小玲 ${ }^{1,2}$, 杨顺 $^{3}$ \\ 1 广东省地理空间信息技术与应用重点实验室, 广州 510070 , 中国 \\ 2 广州地理研究所, 广州 510070 , 中国
} \\ ${ }^{3}$ 中国地质调查局探矿工艺研究所, 成都 611734, 中国}

\begin{abstract}
Debris flow disasters are usually accompanied by serious losses of lives and properties. As one of the important and effective means of disaster non-engineering mitigation measures, disaster management is extremely important for disaster mitigation and sustainable development of economy and society. Taking the Shenshui watershed, Magui town, located in typhoon-hit areas in western Guangdong Province as the study area, the concept of "small watershed functional map" was put forward firstly. Then, its application in debris flow disaster management was discussed based on numerical simulation of debris flows. The results show that disaster management based on "small watershed functional map" can improve the ability of watershed disaster mitigation and provide some references and examples to Chinese debris flow disaster management.
\end{abstract}

Keywords: Risk assessment, debris flow, numerical simulation, disaster management

\begin{abstract}
摘要
泥石流通常带来巨大的人员伤亡和财产损失, 是山区常见的一种灾害。风险管理作为一种重 要的非工程减灾措施, 对于山区防灾减灾和经 济社会的可持续发展具有重要的意义。本研究 以广东粤西台风区马贵镇深水村小流域为研 究区, 提出 “小流域功能图谱” 的概念; 基于 数值模拟的结果, 探讨其在泥石流灾害管理中 的应用。结果表明, 以 “小流域功能区图谱” 为中心的灾害风险管理, 强调生物治理和综合 减灾, 可以提高流域应对灾害的能力, 为我国 泥石流灾害的管理提供借鉴和示范。
\end{abstract}

关键词: 风险分析, 泥石流, 数值模拟, 灾 害管理

1. 引言

泥石流常常具有暴发突然、来势凶猛、迅 速之特点, 并伴生崩塌、滑坡和洪水破坏, 其 危害程度比单一的崩塌、滑坡和洪水的危害更 为广泛和严重 ${ }^{[1]}$, 是山区常见的一种灾害。其 形成不仅受地质、地貌、岩性等因素的控制, 也与气象、人文等因素息息相关。近年来, 我 国多次发生特大泥石流灾害, 给山区人民的生 
命财产、生态环境等造成了严重的危害。经统 计, 2001 年至 2012 年我国总共发生泥石流 11399 次, 造成 5155 人死亡和失踪, 直接经 济损失高达 54.5 亿元 ${ }^{[2]}$ 。如 2010 年“8.7”舟曲 特大泥石流灾害, 造成 1434 人遇难和 331 人 失踪 ${ }^{[3]}$ 。

泥石流风险管理是一个非常重要的泥石 流非工程防灾减灾手段 (柔性措施), 在经济 能力不够、治理技术不成熟、防治效果不确定 时, 可以有效地降低泥石流造成的风险, 提高 居民、建筑物等受灾对象的抗风险能力。风险 管理早已在经济学领域得到了广泛的应用, 但 是真正应用到灾害的管理中是近 30 年的事。 ISO/CD31000 标准将风险管理分为管理框架、 风险评价(含风险识别、风险分析及风险估计)、 风险处置等 3 个方面 ${ }^{[4]}$ 。殷杰等认为基于灾害 风险理论的风险管理应该由风险辨识、风险分 析、风险评估和风险减缓等 4 部分组成 ${ }^{[5]}$ 。向 喜琼(2000)和黄润秋(2002)等人在充分借鉴发 达国家和地区边坡安全管理经验的基础上, 提 出尝试从区域上对滑坡地质灾害进行风险评 价和风险管理的基本构想 ${ }^{[6-7]}$ 。

灾害风险管理的范围极其广泛, 内容极其 丰富、层次极其复杂, 无通用模型, 目前的研 究只要集中在某些部分 ${ }^{[8-10]}$, 在防灾减灾实际 工作中, 仍然缺乏泥石流灾害风险管理的科学 理论和技术支撑。随之社会经济的不断发展, 人类活动强度的增加以及全球环境的变化, 使 得灾害致灾因子的不确定性增加、承灾体的暴 露性和脆弱性增强、灾害风险呈现空间扩大和 强度增加的趋势。因此, 亟需开展相关研究, 提升灾害风险管理的水平, 从而有效地防范泥 石流灾害的发生和减轻灾害损失。

\section{2. 研究区概况}

马贵镇位于广东省高州市东北部山区, 东 与阳春市双空镇相邻, 北与信宜市钱排、合水 镇接壤, 西与古丁镇、南与大坡镇相连, 处于 3 市交界地带, 地理位置如图 1 所示。马贵镇 地貌为低山高丘区, 高程范围在 $183.3 \mathrm{~m}$ $\sim 1632.6 \mathrm{~m}$ 之间, 马贵镇地处南亚热带季风区, 受南海海洋性气候影响, 是台风活动侵袭经过 的地区之一。多年平均降雨量 1700 多毫米, 多年平均气温 $21.3 \sim 23.2{ }^{\circ} \mathrm{C}$, 年无霜期平
均为 $361 \mathrm{~d}$, 多年平均日照时间 $1935.3 \mathrm{~h}$ 。岩 性以花岗岩、片麻岩及其风化物为主, 部分为 页岩 ${ }^{[11]}$ 。

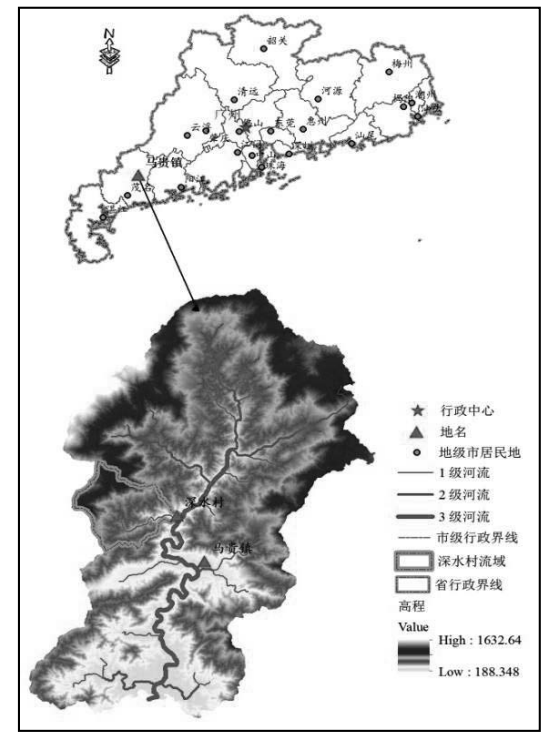

图 1 研究区地理位置

2010 年 9 月受超强台风“风比亚”的影响, 马贵镇出现特大暴雨, 造成马贵镇多处发生山 体滑坡、崩塌、泥石流等灾害, 受灾严重, 灾 害给马贵镇造成了重大财产损失和人员伤亡, 同时也对自然生态环境造成了巨大破坏。灾后 通过对马贵镇的多次考察, 发现深水村流域发 生了大面积的崩塌和滑坡, 受灾严重, 而且流 域内居民人数较多、脆弱性较高、很容易遭受 灾害的冲击、淤埋等风险, 因此, 其风险管理 势在必行。因此将深水村选为典型研究区, 流 域的地理位置如图 1 所示, 流域高程范围在 $357.7 \mathrm{~m} \sim 1293.6 \mathrm{~m}$ 之间, 坡度在 $0^{\circ} \sim 58.34^{\circ}$ 之间。

\section{3. 泥石流灾害的数值模拟}

泥石流的受灾范围主要通过数值模拟的 方法取得, 受灾范围内的泥石流流速、泥深, 承灾体的属性等决定着泥石流的风险大小。本 研究采用数值模拟的方法对不同降雨频率下 的泥石流淹没范围、流速、泥深等进行数值模 拟, 在此基础上, 根据最终的淤埋泥深和不同 属性的土地利用类型, 建立泥石流风险分析标 
Risk Analysis and Crisis Response in Big Data Era (RAC-16)

准，绘制最大淹没范围下的泥石流风险图。

数值模拟所需的基本数据主要为: 3D 数 字地形模型、泥石流流变特性、泥石流流量过 程或者泥石流流体体积、泥石流暴发的源区位 置或者最小高程。3D 数值模拟平台可以通过 GPS、三维激光扫描仪等进行实地野外测绘获 取, 还可以通过航空摄影手段, 通过高精度的 航空影像提取。本研究建立的马贵镇深水村 $3 \mathrm{D}$ 数值模拟平台如下图 2 所示。泥石流流变 特性通过采集泥石流样品和室内的流变实验 来确定。泥石流暴发的源区位置, 结合遥感影 像数据和野外调查的成果来确定。

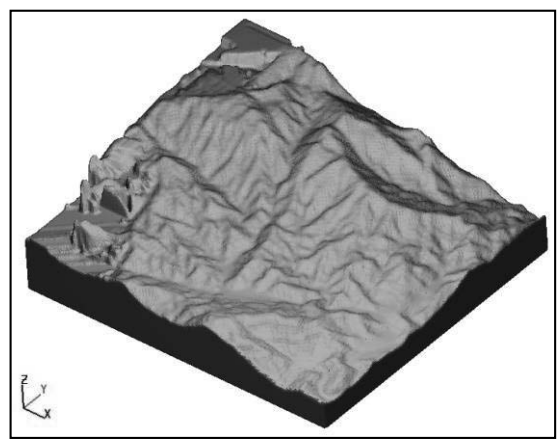

图 2 马贵镇深水村 3D 数值模拟平台

高桥保（1980）提出的泥石流等效浓度的 计算公式 ${ }^{[12]}$ :

$$
C_{d \infty}=\frac{\rho \tan \theta}{(\sigma-\rho)(\tan \phi-\tan \theta)}
$$

式中, $C_{d \infty}$ 为泥石流体的等效浓度, $\rho$ 为泥石 流液相流体的密度（液相为水, $\rho=1.0 \mathrm{~g} / \mathrm{cm}^{3}$; 液相为粘性流体, $\left.\rho=1.2 \mathrm{~g} / \mathrm{cm}^{3}\right), \theta$ 为沟床平 均坡度, $\sigma$ 为泥石流固体颗粒密度, 通常情况 下取 $2.65 \mathrm{~g} / \mathrm{cm}^{3}, \phi$ 为固体颗粒的内摩擦角。

一般而言, 泥石流的体积由野外起动的松 散固体物质的体积和降雨径流量的体积叠加 而成, 假设野外可以起动的松散固体物质的体 积为 $V_{s}$, 不同降雨条件下的降雨量为 $V_{w}$, 则 泥石流的总体积 $V_{D}$ 通过下式进行计算 ${ }^{[13]}$ :

$$
V_{D}=\min \left\{\frac{V_{s}}{C_{d \infty}}, \frac{V_{w}}{1-C_{d \infty}}\right\}
$$

上式中的野外可以起动的松散固体物质的体 积 $V_{s}$, 通常由遥感影像数据和野外调查的成果 来确定, 不同降雨条件下的降雨量 $V_{w}$ 通过查
询水文手册和水文计算求得; 泥石流流体的等 效浓度 $C_{d \infty}$ 通过 GIS 三维空间分析功能获取流 域空间数据 $\theta$, 通过室内外实验获取泥石流流 体 $\rho$ 和固体颗粒物质的 $\phi 、 \sigma$ 数据。通过计算, 本研究的等效浓度 $C_{d \infty}$ 为 0.58 , 最大泥石流体 积 $V_{D \text { max }}$ 为 $2058190 \mathrm{~m}^{3}$, 若有极端降雨 (台风 等), 由于松散固体物质的限制, 可以起动的 泥石流最大体积仍为 $V_{D \text { max }}$, 那么, 估算的泥石 流在不同降雨条件下的最大体积 (最大体积对 应不同降雨条件下, 泥石流最大淹没范围和造 成的最大损失)，如下表 1 所示

表 1 研究区不用降雨条件下的泥石流体积估算表

\begin{tabular}{cccc}
\hline $\begin{array}{c}\text { 不同降雨频 } \\
\text { 率/年 }\end{array}$ & 50 & 100 & 500 \\
\hline $\begin{array}{c}\text { 最大泥石流 } \\
\text { 体积 } / \mathrm{m}^{3}\end{array}$ & 400000 & 1000000 & 2058190 \\
\hline
\end{tabular}

通过流变实验, 研究区泥石流流体流变特 性为 Bingham 型, 流体的参数设置如表 2 。

表 2 泥石流流体属性表

\begin{tabular}{ccccc}
\hline $\begin{array}{c}\text { 泥石流 } \\
\text { 性质 }\end{array}$ & $\begin{array}{c}\text { 容重/ } \\
\mathrm{g} / \mathrm{cm}^{3}\end{array}$ & $\begin{array}{c}\text { 沟床 } \\
\text { 粩度 }\end{array}$ & $\begin{array}{c}\text { 屈服应 } \\
\text { 力 } / \mathrm{Pa}\end{array}$ & $\begin{array}{c}\text { 粘度系数 } \\
/ \mathrm{Pa} \cdot \mathrm{s}\end{array}$ \\
\hline Bingham & 1.65 & 0.1 & 20 & 0.5 \\
\hline
\end{tabular}

在上述数值模拟参数设定的基础上, 通过 网格划分和边界条件的设置, 开展泥石流数值 模拟, 对不同降雨条件下的淹没范围、泥石流 淤埋深度和流速等参数进行模拟。不同降雨条 件下的泥石流淹没范围和流体流速分布如图 3 所示。由于文章篇幅限制, 泥石流的流深图此 处不在文章中罗列。

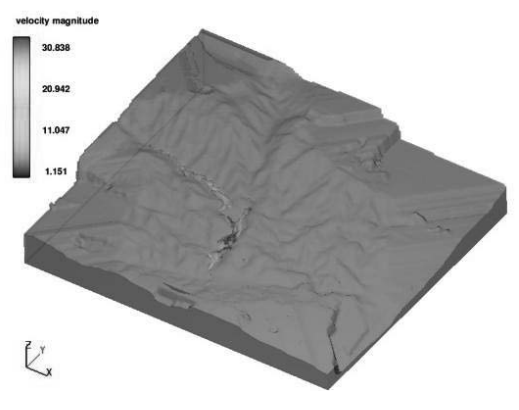

（a） 50 年一遇频率 
Risk Analysis and Crisis Response in Big Data Era (RAC-16)

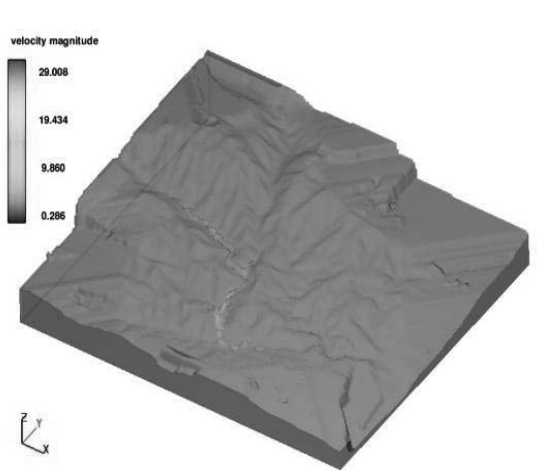

（b） 100 年一遇频率

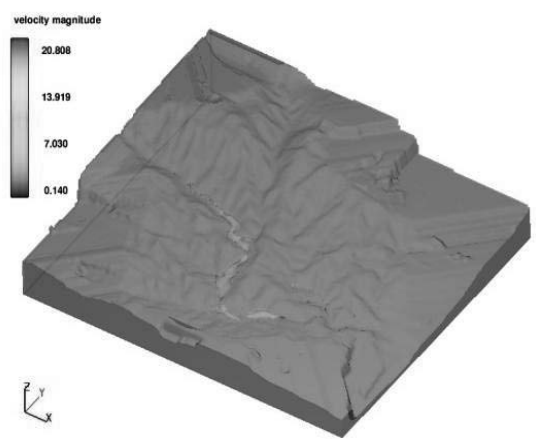

（c） 500 年一遇频率

图 3 不同降雨条件下的淹没范围和流速分布图

以最大的泥石流淹没范围和泥深为基础, 针对不同的土地利用属性的承灾体 (图 4), 建立风险评估标准 (表 3), 绘制 500 年一遇 降雨频率下的泥石流风险图（图 5)。

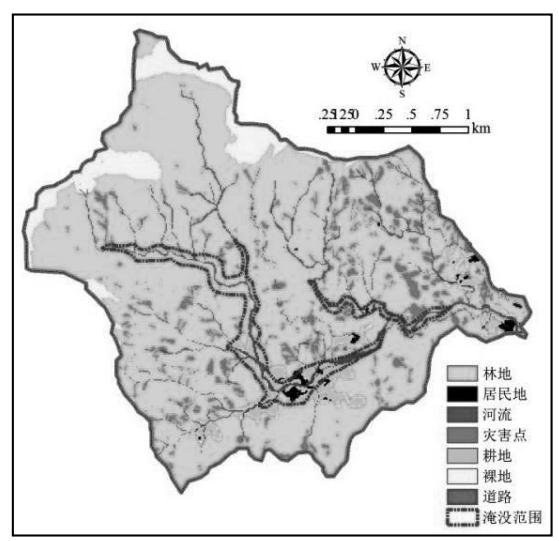

图 4 深水村流域土地利用分布图
表 3 不同属性承灾体的泥石流风险分析标准

\begin{tabular}{|c|c|c|c|c|}
\hline $\begin{array}{c}\text { 淤埋泥深 } \\
\text { /m }\end{array}$ & $\begin{array}{c}\text { 居民 } \\
\text { 点 } \\
\end{array}$ & 林地 & 耕地 & 道路 \\
\hline$>2$ & 高 & 高 & \multirow{2}{*}{\multicolumn{2}{|c|}{ 高 }} \\
\hline $1<\mathrm{h} \leq 2$ & 中 & 中 & & \\
\hline $0.5<h \leq 1$ & \multirow{2}{*}{\multicolumn{2}{|c|}{ 低 }} & 中 & 中 \\
\hline$\leq 0.5$ & & & 低 & 低 \\
\hline
\end{tabular}

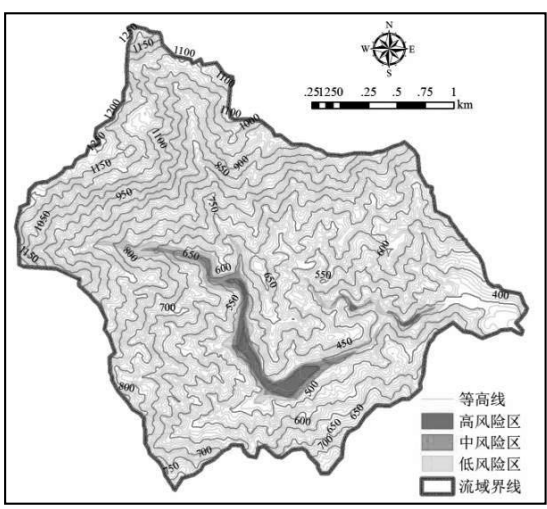

图 5500 年一遇降雨频率条件下的泥石流风险图

\section{4. 小流域功能图谱}

根据泥石流的流域特征, 可以将单沟泥石 流划分为形成区、流通区和堆积区。不同分区 的地貌形态、地势起伏、沟床物质条件等特征 不同, 其承担的泥石流防治功能也不同。此处 定义: 将一个泥石流小流域不同分区承担的防 治泥石流功能的总和, 称为小流域防灾减灾功 能图谱。可以看出, 该功能图谱以不同泥石流 流域分区为基础, 分为三个组成部分:

(1) S 功能区: 即泥石流形成区对应的功 能区, 主要承担的是防止泥石流发生的功能。 泥石流形成区主要是泥石流水源、土源或砂石 供给和起始源地, 该功能区通过采取治坡、治 沟、护坡等措施, 以及行政管理和法令措施, 对流域实施综合治理, 保持水土、恢复生态, 达到防止泥石流的功能。此功能区主要强调生 物治理。

(2) T 功能区: 即泥石流流通区对应的功 能区, 主要承担控制泥石流运动的功能。流通 区是泥石流形成后, 向下游集中流经的必经地 区, 该功能区主要通过拦挡、调节和排导等工 程, 使泥石流顺利通过或到达指定的地区, 达 
到保护居民地等受灾对象的功能。此功能区主 要强调的是工程措施。

(3) F 功能区: 即泥石流堆积区对应的功 能区, 主要承担预和减轻泥石流危害的功能。 泥石流堆积区是泥石流碎屑物质大量淤积的 地区, 堆积扇也常常是山区人类活动的主要场 所所在地, 该功能区通过采取一些预警预报和 预防措施, 使泥石流在活动过程中不致引起较 大危害, 将泥石流的危害降至最低。

三个功能区相辅相成, 相互关联, 在具体 应用时, 要在三个功能区进行统一规划和布局, 使得其发挥最大的功能, 达到泥石流防治的目 的。根据泥石流数值模拟的淹没范围结果, 结 合流域特征, 深水村泥石流小流域的功能图谱 划分如图 6 所示。

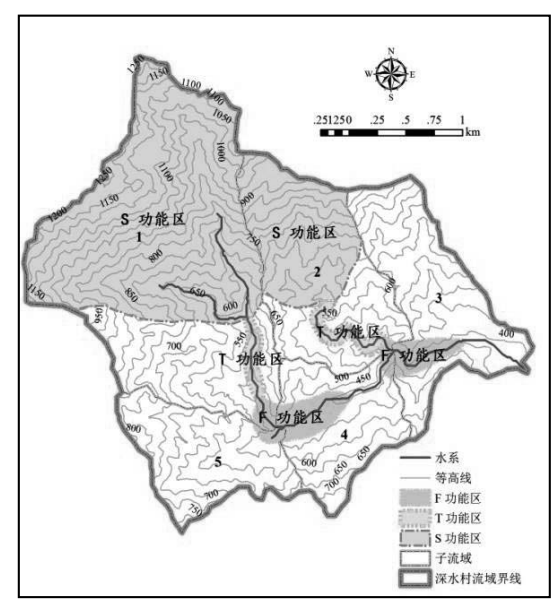

图 6 深水村泥石流小流域功能图谱

\section{5. 泥石流风险管理}

根据泥石流风险的大小, 以小流域功能图 谱为中心, 开展泥石流风险管理的研究。具体 的管理措施如图 7 所示。

(1) $S$ 功能区:

在 S 功能区严密监控泥石流的水源、土源。 采用自记雨量计、自计土壤仪、三角堰等对泥 石流的水源、雨量、土壤水、径流量进行监测, 采用 GPS 等仪器对泥石流源区土体变形进行 监测, 采用红外摄像仪对泥石流源区的土源、 水源和泥石流的形成过程进行监测。

在 S 功能区通过行政管理和法令措施, 禁 止滥砍乱伐、开屋荒地; 恢复乔、灌、草保持
水土的功能; 在荒地因地制宜种植乡土植物, 恢复生态; 在崩滑、泥石流源地, 沟坡土层浅 薄、质地差、成土过程短、土层含水量较小, 处于干燥贫痊状态, 必须用植被覆盖, 可选择 护坡林, 沿坡脚至分水岭的坡面, 沿等高线种 植, 并以造灌木林为主, 辅以藤本和草木, 同 时选择耐贫痊、生长快、根系发达的植被, 以 保持水土、恢复生态, 达到防止泥石流的功能。

在 S 功能区上游崩滑严重的地区和水土 流失严重的地区, 为了节流固床护坡, 修建梯 级谷坊群; 在主沟和较大之沟, 布置拦砂坝; 为了防止坡脚冲刷和新的崩塌、滑坡发生, 需 进行治坡工程和护坡工程。

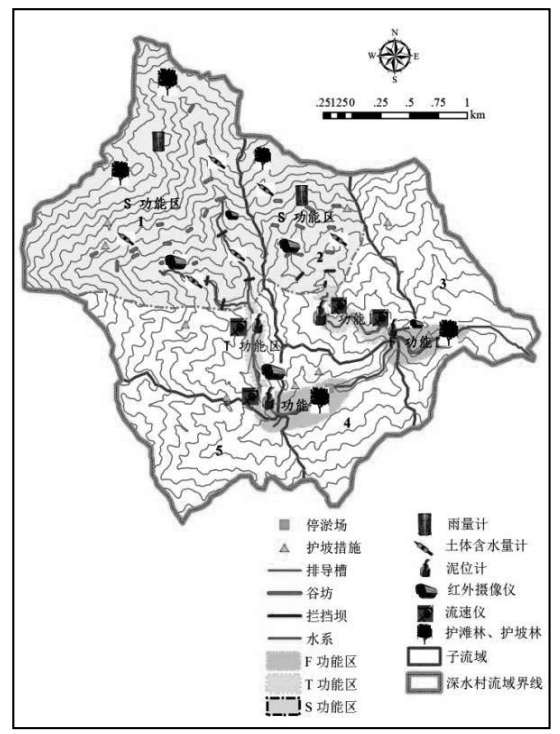

图 7 深水村泥石流灾害风险管理措施分布图

(2) T 功能区:

$\mathrm{T}$ 功能区是对泥石流的流量、泥位、流速 等运动特征参量进行监测。一般采用超声波泥 位计对泥石流运动过程中的泥位进行监测, 采 用测速仪对泥石流运动过程中的流速进行监 测, 采用红外摄像仪, 对泥石流运动过程进行 监测。

在 $\mathrm{T}$ 功能区必须建立排导槽等工程措施, 对流经人类活动范围的泥石流流体进行疏导， 使之能到达指定区域, 而不危害人类的生命、 财产等。

(3) F 功能区: 
Risk Analysis and Crisis Response in Big Data Era (RAC-16)

深水村流域堆积区是人类活动非常密集 的场所, 因此, 泥石流对人类的生命财产安全 构成了严重的威胁, 在泥石流堆积区的范围内, 设置相应的监测预警、生物和工程措施，尽可 能的减轻泥石流对该区人民生命财产安全带 来的危害。

F 功能区主要是对泥石流运动特征进行 监测, 如采用超声波泥位计对泥位进行监测, 采用测速仪对泥石流运动过程中的流速进行 监测, 采用红外摄像仪, 对泥石流泛滥堆积过 程进行监测。

在泥石流出口以外的堆积扇, 为了阻滞泥 石流流体及石块的运动, 保护滩地上的农田及 其其他设施, 栽植护滩林, 宜采用乔灌木混交, 这样既可以恢复生态景观, 还可以阻滞洪流拦 蓄泥沙和阻挡大石块的搬运。

根据泥石流运动和堆积特征, 设置泥石流 停淤场, 将泥石流引入指定区域, 令其自然减 速, 减轻其造成的危害; 同时, 严格控制在在 功能区的人类活动建设, 以防止造成重大的人 员伤亡和经济损失。

\section{6 结论}

通过数值模拟, 对马贵镇深水村流域不同 降雨条件下的泥石流运动过程进行了数值模 拟, 得到了淹没范围、泥深、流速等的分布; 根据数值模拟结果, 结合不同属性的土地利用 类型, 建立了泥石流风险分析标准, 得到了泥 石流的风险图。

提出了“小流域功能图谱”的概念, 将泥石 流小流域划分为 $\mathrm{S}$ 功能区、 $\mathrm{T}$ 功能区和 $\mathrm{F}$ 功能 区, 开展以“小流域功能图谱”为中心的泥石流 灾害风险管理研究, 强调生物治理和综合减灾, 可以提高流域应对灾害的能力, 为我国泥石流 灾害管理提供借鉴和示范。

\section{致谢}

资助项目: 广东省水利厅科技创新项目 (2016-15)、广东省科技计划(2015B070701020、 2013B03070005、2014A020218013、2013B0315 00007、2013B020314003)。

\section{参考文献}

[1] 李小雪. 泥石流灾害风险管理现状及对 策研究.人民长江,2013,44(4): 103-106.

[2] 乐茂华. 强震区溃决型泥石流动力过程 模拟及特征研究[D].成都理工大学,2014.

[3] 360 百科. 8.7 甘肃舟曲特大泥石流. http://baike.so.com/doc/4467616-4676432. html.

[4] ISO 31000: 2009 (E). Risk managementPrinciples and guidelines.

[5] 殷杰, 尹占娥, 许世远, 等. 灾害风险理 论与风险管理方法研究. 灾害学, 2009, (2) : $7-11$.

[6] 黄润秋, 向喜琼. GIS 技术在生态环境地 质评价中的应用. 地质通报，2002，(2): 98-101.

[7] 向喜琼, 黄润秋. 地质灾害风险评价与风 险管理。地质灾害与环境保护，2000, 11(1): 38-41.

[8] D. Kashiwagi, J. Kashiwagi. A new risk management model. Journal of Risk Analysis and Crisis Response, 2012, 2(4): 233-251.

[9] V. Sousa, N.M.D. Almeida, L.A. Dias. Risk management framework for the construction industry according to the ISO 31000:2009 standard. Journal of Risk Analysis and Crisis Response, 2012, 2(4): 261-274.

[10] G. Tuladhar. Disaster management system in Nepal-policy issues and solutions. Journal of Risk Analysis and Crisis Response, 2012,2(3): 166-172.

[11] 王永喜, 夏兵. 粤西台风灾区水土保持生 态修复策略和措施一以高州市马贵镇为 例. 中国水土保持科学, 2012, 10(1): 88-93.

[12] T. Takahashi. Debris flow on prismatic open channel. J Hydraul Div ASCE, 1980, (HY3): 381-396.

[13] K.F. Liu, H.C. Li, Y.C. Hsu. Debris flow hazard assessment with numerical simulation. Natural Hazard, 2009, 49: 137-161 